\title{
Beyond the Research-Practice Gap: The Development of an Academic Collaborative Centre for Child and Family Social Work
}

\author{
Roos Steens ${ }^{1, *}$, Tine Van Regenmortel ${ }^{1,2,3}$ and \\ Koen Hermans ${ }^{1}$
}

\author{
${ }^{1}$ Centre for Sociological Research, Faculty of Social Sciences, University of Leuven, 3000 \\ Leuven, Belgium \\ ${ }^{2}$ HIVA, KU Leuven, 3000 Leuven, Belgium \\ ${ }^{3}$ Academic Collaborative Centre Social Work, Tranzo Tilburg University, 5037 AB Tilburg, \\ The Netherlands
}

*Correspondence to Roos Steens, Centre for Sociological Research, Faculty of Social Sciences, University of Leuven, Parkstraat 45 bus 3600, 3000 Leuven, Belgium. E-mail: Roos.steens@kuleuven.be

\begin{abstract}
The gap between research and practice has been a long-standing challenge in social work (e.g. Richmond, 1917; Rubin, 2014). Partnership structures between research facilities and social care organisations are seen as a possible way forward, but knowledge on how such partnerships can be successfully elaborated and implemented in local social work practices is scarce. In this article, we elaborate on our experiences in building an academic collaborative centre (ACC): a long-term partnership between a social service organisation and a university (see also ACCs for public health in the Netherlands, e.g. Garretsen et al., 2007; Molleman and Fransen, 2012; Jansen et al., 2015). Starting from the conceptual framework of Thompson et al. (2009), we open up the black box of our collaboration project and give insight into what turned out to be a long and messy but also a very rich and insightful process. We conclude by identifying three important aspects to implementing a research-practice partnership in local social work practice: (i) informal contacts between the different stakeholders and knowledge brokering, (ii) collaborative research projects and (iii) a general framework of mutuality and agreement in which differences can safely exist and negation can take place.
\end{abstract}


Keywords: Partnerships, research-practice gap, evidence-based practice, knowledge co-creation, academic collaborative centre

Accepted: August 2017

\section{Introduction}

Although arguments for improving the extent to which social work practice is informed by research have been advanced for nearly a century (e.g. Richmond, 1917) and there is increasing attention for evidencebased practice in social work, the gap between research and practice has persisted (Nutley et al., 2003, 2009; Rubin, 2014).

An extensive body of literature approaches this research-practice gap from the perspective of knowledge/transfer/translation/exchange (Van Egmond, 2010; De Goede, 2011; Gray et al., 2015). We can distinguish between linear models, relationship models and system/network models (Wehrens, 2013, p. 17). Linear models describe a one-way process in which researchers produce knowledge, which is then disseminated among and implemented by practitioners. This body of literature frames the gap between research and practice as a problem of knowledge translation (Gray et al., 2015). Relationship models focus on the interactions that are required to increase research utilisation. Solutions from this approach are often framed as building bridges or knowledge brokering (Van Egmond, 2010; De Goede, 2011; Gray et al., 2015). System/network models focus on the structures in which science-policy interactions are embedded, shaped and organised (Best and Holmes, 2010). Their focus is not only on the interactions, but also on the arena in which these actions take place (De Goede, 2011). These three models, however, approach research and practice as if they were two separate worlds.

The model of co-production or the partnership approach takes a completely different turn. Here, evidence and evidence use are approached as a process: '. . r rather than evidence-based, it is the process of evidence-basing that becomes interesting' (Wehrens, 2013, p. 32). Nutley describes this as research in practice, in contrast to research into practice. Research into practice sees evidence as something external to the world of practice, whereas research in practice sees the process of evidence generation and professional practice as much more intimately involved (Nutley, 2003, p. 132), with researchers and practitioners collaborating in the production, implementation, dissemination and validation of knowledge (Osterling and Austin, 2008; De Goede, 2011). Nutley describes the organisational excellence model as the organisational vehicle to enhance this collaboration between research and practice. Its main characteristic is the development of a structural and 
long-term partnership between a research institute and a social service agency to enable a continuous learning process in which knowledge is 'collaboratively interrogated, tested, adapted, adopted and evaluated' (Kitson, 2009, p. 128).

Partnership structures between social work research and practice are popping up in different countries and are increasingly institutionalised (e.g. Collaborative Practitioner Research Networks Initiative in Denmark, Partnership for Improved Social Services in Norway (HUSK), ACCs in the Netherlands). However, the discussion on such partnerships has mainly focused on why they are important and not so much on how they can be conceptually elaborated and which tensions, concerns and dilemmas arise when they are implemented in local social work practice.

In this article, we elaborate on our experiences (first author was involved as a science practitioner in the ACC and the second and third authors as supervisors) in building an academic collaborative centre (ACC): a long-term partnership between a social service organisation and a university (regarding ACCs for public health in the Netherlands, see e.g. Garretsen et al., 2007; Molleman and Fransen, 2012; Jansen et al., 2015). We start by elaborating on the origins, goals and conceptual framework of the ACC, and then move on to describe the process to implement the ACC in local social work practice.

\section{The ACC}

\section{Originated from a dissatisfaction with the narrow approach to evidence-based practice}

Over the past ten years in Flanders, youth care services have been subject to growing pressure and demands to adopt 'evidence-based practice' (EBP). However, EBP is often equated with the use of empirically supported interventions: '.. manualised interventions for which a body of research evidence on the effectiveness of outcomes has been compiled' (Gray et al., 2012, p. 158). This entails a very narrow, 'cookbook approach' to EBP, which involves extracting best practices from scientific literature and simplistically applying them in social work practice. An organisation for child and family social work in Antwerp struggled with these increasing demands for accountability and the narrow approach of EBP. They expressed the need to work towards a more 'research informed practice', beyond the traditional one-way process in which researchers produce knowledge, which is then disseminated among and implemented by practitioners. To provide a sound answer to this question, a concept that originated in the Netherlands was adopted and further developed: the ACC. 


\section{Inspired by a concept from the Netherlands}

In 2005, the Dutch Ministry of Health made fourteen million Euros available for the establishment of ACCs (Garretsen et al., 2007; Molleman and Fransen, 2012, p. 158). These ACCs are long-term partnerships between one or more regional public health services, municipal departments and university departments. Hoeijmakers et al. (2013, p. 175) describe their main objective as 'to improve knowledge exchange between policymakers, researchers and practitioners in order to increase the production of socially relevant scientific knowledge and the utilization of such research evidence in policy and practice'.

Molleman and Fransen (2012) describe five key elements of ACCs:

1. a contractual agreement to guarantee a long-term partnership between public health services and university;

2. employees with double appointments at a public health service and university;

3. involvement of senior researchers and professors in the centre;

4. research based on questions relevant to everyday public health practice;

5. an intention for the collaborative centre to continue the partnership after a second four-year phase of the programme.

Wehrens (2013, p. 36) reports that ACCs are often described as boundary organisations (Guston, 1999, 2001) (Figure 1). Boundary organisations are 'formal institutions organized at the intersection of divergent social groups to broker or mediate interactions across a border of diverse purposes, incongruent values and potential incomprehension' (Parker and Crona, 2012, p. 265). A boundary organisation coordinates different social worlds, while remaining accountable to each of them. It creates and serves as an internal room for negotiations over meanings, concepts and goals.

Since the development of ACCs for public health, ACCs are 'booming business' in the Netherlands and are popping up in different fields: youth care, mental health, social work, youth detention, addiction care. Most ACCs, however, are primarily collaborative structures that encompass very different research projects. There seems to be no real or unifying theoretical content that creates conditions, indicates the direction and sets a common approach. Inspired by the development of ACCs in the Netherlands, a small-scale academic collaborative centre was developed in Flanders, Belgium. This ACC links an organisation for child and family social work in Antwerp with two research institutes at the University of Leuven. The ACC in Flanders, however, moves beyond the two-communities perspective (research and practice as two separate worlds that need to be bridged or brokered) to explore the possibility of actually dissolving the boundaries between science and practice. 


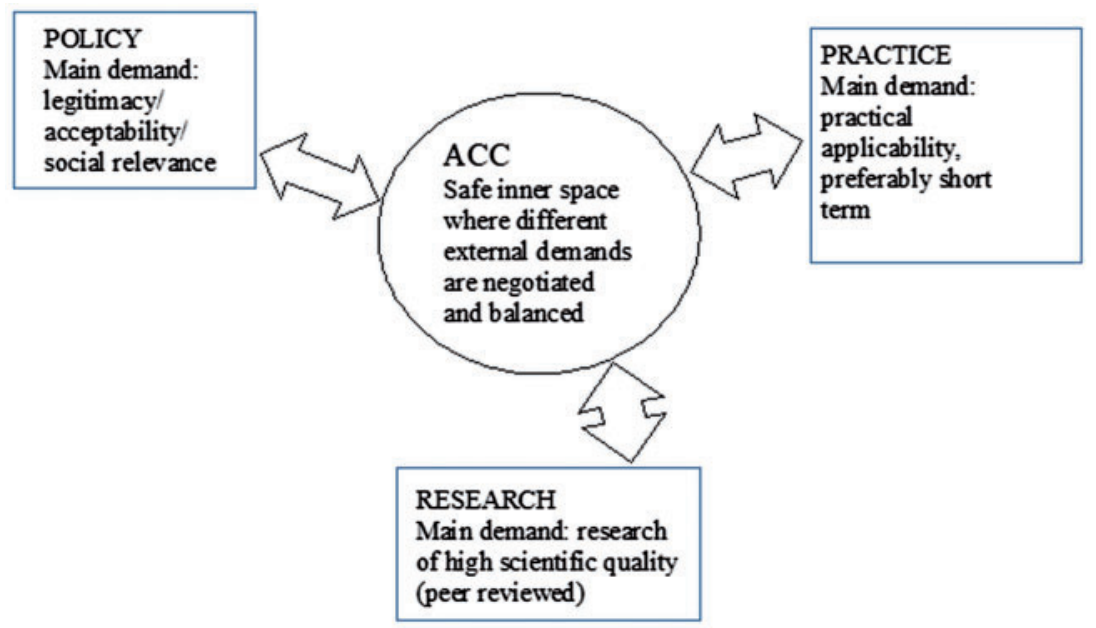

Figure 1: ACGs as boundary organisations (Wehrens, 2013, p. 37)

\section{Goals and theoretical framework}

The ACC in Flanders has both an instrumental and a cultural goal (e.g. Biesta, 2007): (i) to build knowledge about enabling and restricting mechanisms that can explain the impact of social interventions, thereby contributing to the general knowledge base of our discipline and enhancing practice improvement; and (ii) to facilitate the formation of a learning organisation (Senge, 1990) where critical questions are raised, different ways of understanding social reality are combined and stakeholders work collaboratively towards a better quality of care. To meet these goals, various frameworks are combined: a framework of cocreation, a realist approach to effectiveness and an empowerment framework.

At the core of the ACC is the concept of co-creation. Knowledge is not seen as something static that belongs to the academic world and that needs to be transferred to the world of practice. Different forms of knowledge are combined, from the assumption that each perspective offers a valuable entry point for understanding social processes (Longhofer et al., 2013). Congruent with Nutley et al. (2003, p. 132) research-in-practice model, the focus is on interactions, with partnerships facilitating two-way exchanges (Belkhodja et al., 2007); researchers and practitioners collaborate in the production, implementation, dissemination and validation of knowledge (Osterling and Austin, 2008; De Goede, 2011). Gredig and Sommerfeld (2008) follow the same path and describe a process of hybridisation. In this process, different forms of knowledge are combined to form an endless cycle of knowledge 
production and utilisation, in which the process of using research leads to the co-creation of new knowledge, and so on. This produces knowledge that is neither research nor practice-based, but both.

Second, we use a broad, ecological and realist approach to the effectiveness of social interventions. We explicitly give attention to how context shapes social interventions and outcomes. This means that we take an explanatory turn in our research projects. Rather than asking 'does it work?', we ask 'for whom, under which circumstances and how does it work?' (see Pawson, 2006, 2014; Kazi, 2000, 2003; Blom and Morén, 2010). This realist approach is particularly valuable because it recognises the dynamic, multi-layered nature of everyday social work and connects with the desire of social workers to grasp this reality and enlarge the impact of their interventions. At the same time, it fits in with the task of researchers to contribute to the knowledge base of social work and to build knowledge that can be disseminated more widely.

Third, the theoretical framework of the ACC is grounded in empowerment theory. This broad philosophical and ethical framework is congruent with the broad ecological approach described above. The empowerment theory connects the individual (personal and psychological empowerment; Zimmerman, 1990a, 1990b, 1995) with the organisation (organisational empowerment; Zimmerman, 2000) and the broader community (community empowerment or political empowerment; Gerschick et al., 1990). Within this multilevel framework, empowerment can be defined as 'a process by which people, organizations and communities gain mastery over their life and their surroundings by acquiring control, building critical understanding and through participation' (Van Regenmortel et al., 2016, p. 9). Consequently, research performed within this framework (empowerment research) shares its ownership between all stakeholders involved and explicitly seeks to strengthen 'the silenced voices', namely the voices that traditional research projects generally fail to take into account. Empowerment research adds to the framework of co-creation and the broad view on effectivity, and adds an explicit ethical/moral dimension to the ACC. It claims that research cannot be limited to building knowledge, but should also be about social justice. Socially vulnerable groups should be a priority, as well as the themes that are relevant to them like marginalisation, segregation, quality and accessibility of care (Van Regenmortel et al., 2016).

\section{The process of building an ACC}

Although the theoretical framework of the ACC was built fairly quickly, implementing this framework in practice turned out to be a long, messy, iterative and dynamic process (see also Huxham and Vangen, 2000). 
This contrasts with more traditional, linear or stage models of the collaboration process (e.g. Gray, 1989; Edelenbos and Klijn, 2005). To give insight into this process, we use the theoretical model of collaboration developed by Thompson et al. (2009). They describe five key dimensions of collaboration: (i) governance, (ii) administration, (iii) organisational autonomy, (iv) mutuality and (v) norms.

\section{Governance: a multi-stakeholder collaboration structure, a continuous process of negotiation, knowledge brokers}

According to Thompson et al. (2009), collaboration requires creating structures that allow participants to jointly make decisions, solve problems and develop sets of working rules. In the ACC, this governance is realised through a multi-stakeholder collaboration structure for researchers, the social service agency management, social workers and service users. This collaboration structure was built from the beginning of the project and consists of a guiding board, two supporting groups and an expert commission:

- the guiding board consists of members of the management of the organisation for child and family social work, representatives of the social work practitioners and researchers. Meetings are held every ten weeks and consist of negotiations regarding the development of the ACC, discussions about the operationalisation of research projects and the (validation of) results;

- the supporting groups consist of: (i) a group of social work practitioners from the different departments of the organisation, chaired by the representatives of the social workers that are part of the guiding board and (ii) a second group of representatives from three independent user organisations. In the supporting groups, the problems, concerns and dilemmas that are encountered in the guiding board as well as concrete plans and operationalisations and research project results can be discussed;

- the expert commission comprises representatives from the juvenile court, educators, policy makers, representatives from the user organisations and researchers from other universities. This group serves as an outsider's eye that monitors the development of the ACC.

Within this collaboration structure, a continuous process of negotiation took place. One crucial element was the process of breaking down stereotypes (see also Ansell and Gash, 2008). For example, at the start of the project, the practitioners were convinced that the research would not produce any benefit for them, and service users believed the social service agency management would not make fundamental changes. 
What turned out to be helpful to breaking down these stereotypes were the discussions held through the collaboration structure, but also the informal face-to-face contacts between the different stakeholders. Getting to know each other outside the formal meetings helped to form a connection and build mutual trust. Another essential element in this process was the role of a science practitioner or knowledge broker Lomas, (2007). From the start of the research project, it was decided that the research projects in the ACC had to be carried out by science practitioners (Figure 2). Science practitioners have experience in both social work research and practice, and fit in with the ACC as a critical friend: a friend who connects with the different stakeholders, negotiates between the mutual expectations and challenges them by posing critical questions (Van Regenmortel et al., 2016).

Since the science practitioner/researcher divided her time between the organisation for child and family social work and the research institutes, she was able to maintain informal contacts with all stakeholders, to sense problems and to raise these problems for discussion through the multi-stakeholder collaboration structure. The task of a science practitioner is very demanding, however. The science practitioner in this case reported feelings such as being in the middle and standing alone. She described 'being a researcher in the organization for child and family social work and being a practitioner in the research organization'. In addition, she struggled with the 'in' and 'out' position of her task and how to remain close to the social workers and the social service agency management, while maintaining the distance required for scientific research. Careful supervision is necessary to fulfil this role properly.

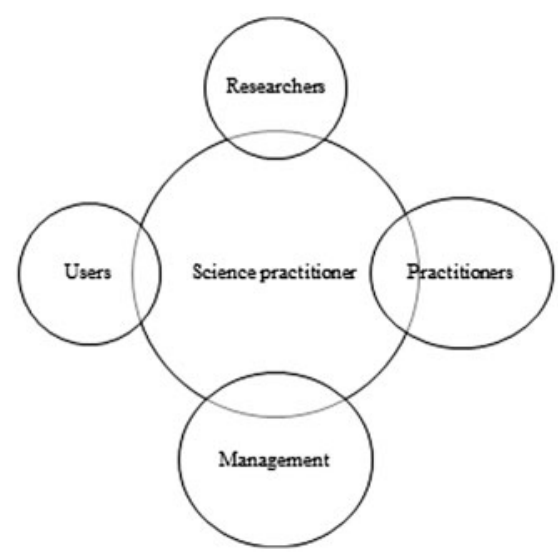

Figure 2: The role of a science practitioner 


\section{Administration: collaborative research projects and diffusion processes}

In addition to a governance structure, collaborations also need an effective operating system to move from governance to action and to achieve the purpose that brought the organisations to the table in the first place (Thompson et al., 2009). Within the ACC, knowledge about underlying mechanisms (instrumental goal) and the foundations of a learning organisation (cultural goal) were built through collaborative research projects which, in turn, triggered unforeseen initiatives at the organisation for child and family social work.

Research projects in the ACC were congruent with the theoretical framework of the Academic Collaborative Centre and included (i) cyclical and dialogical research designs; (ii) realist, explanatory research questions; and (iii) research methods that facilitate a continuous interconnection between practice knowledge, lived experience and scientific knowledge. For instance, in a research project on an intensive family preservation programme, the authors of this paper worked with a triangulation of different research methods like participant observation, in-depth interviews and case-file analyses to build knowledge about the underlying enabling and restricting mechanisms of the programme. The preliminary results from each cycle of data collection were discussed in homogenous dialogue groups with parents, youngsters and social workers and then shared in dialogic conferences. These insights lead to another cycle of data collection. This iterative process between observation and interpretation enabled us to build a strong theoretical framework about generative mechanisms in social work. At the same time, it enhanced a collaborative learning processes between the involved stakeholders.

By facilitating and stimulating interactions between social workers, researchers and service users in specific research projects, stakeholders gradually learned to listen to each other's viewpoints, to speak up and share their ideas. A 'learning organisation culture' gradually developed and took hold throughout the organisation for child and family social work. According to the extensive literature review by Greenhalgh et al. (2004, p. 601), the diffusion of social innovation can be pictured on a continuum between pure diffusion (in which the spread of innovations is unplanned, informal, decentralised and largely horizontal or mediated by peers) and active dissemination (in which the spread of innovation is planned, formal, often centralised and likely to occur through vertical hierarchies). At the ACC, it mainly took the form of pure diffusion. As the ACC became stronger, we observed different unforeseen initiatives at the organisation for child and family social work. For example, the management of the social service organisation organised joint 
brainstorming sessions with parents, youngsters, practitioners, teachers and policy makers to construct a shared mission, vision and values for the organisation. Creative projects were set up through which service users could express their experiences with the organisation. An expert by experience was appointed as a staff member of the organisation. These initiatives in turn stimulated triggered the development of an ACC.

\section{Organisational autonomy: an inherent tension between scientific quality and practical relevance}

A third defining dimension of collaboration that captures both the potential dynamism and frustration implicit in collaborative partnerships is the fact that each partner has a dual identity: they maintain their own distinct identity and organisational authority separate from a collaborative identity (Thompson et al., 2009, p. 26). As a result, there is some tension between organisational self-interest and collective interest. At the ACC, this tension for instance took the form of a continuous balancing act between practical relevance and scientific quality. The management, practitioners and user organisations in the ACC were more focused on practice improvement, whereas the researchers argued for scientific quality and were concerned with transferability and with legitimising the findings. For example, after the first 'taking stock' phase of a research project, the researchers expressed concerns about the involvement of one department of the organisation of child and family social work. The research project was focused on the enabling and constraining mechanisms of a family preservation programme but, due to internal reorganisations, this department was not at the same implementation stage as the other departments. However, the management of the organisation for child and family social work felt very strongly about involving all their departments and practitioners in the research project. This tension between stakeholders went up and down, but never really dissolved. However, as Innes (1999) argues, tension holds within the potential for creativity. Solutions were found in the discussions among stakeholders. In this particular example, the research design was adapted in such a way that allowed the participation of each department.

\section{Mutuality: differing interests within a general framework of agreement}

The fourth dimension of collaboration, according to Thompson et al. (2009), is mutuality. Mutuality can be based on shared interests (homogeneity) or differing interests (complementarity). As mentioned above, 
at the ACC, the management, practitioners and user organisations participated in the research project to enhance local practice improvement, whereas the researchers were also focused on building knowledge and were concerned with transferability and with legitimising the findings. However, these different goals were realised within a general framework of agreement and mutuality, however. This general framework ((i) cocreation; (ii) broad, ecological and realist view on effectiveness; and (iii) empowerment theory) provided the theoretical glue to interconnect the different goals. When the tension between the different stakeholders increased, it proved very helpful to return to this theoretical framework and to re-label 'problems of disagreement' as, for instance, 'opportunities' to create a more complex, nuanced and creative solution. Although there were discussions and disputes about almost everything at the ACC, the theoretical framework was never questioned and proved to be a crucial cornerstone.

\section{Norms: tit-for-tat reciprocity, loops of trust}

The final dimension of collaboration, according to Thompson et al. (2009), concerns norms. In collaboration, participating organisations generally exhibit an 'I-will-if-you-will' mentality, based on the perceived degrees of reciprocal obligations that each will have towards the others. This 'tit-for-tat reciprocity' (Thompson et al., 2009, p. 6) or, in other words, the balance between 'giving and taking' was very present at the different levels of the ACC. Some examples were:

- unforeseen costs at the ACC were always a subject of discussion. Usually they were split evenly between the research institutes and the organisation for child and family social work but, whenever this was not the case, it caused a lot of tension and frustration among the different partners;

- during the first stage of the research project about intensive family preservation programmes, the multi-stakeholder meetings were all about creating the research plans, which caused much frustration among the practitioners. The practitioners wondered openly about their busy schedule and the benefits for them. During later stages of the research project, the researchers invested in intermediate communication and discussion about concrete research data, which was perceived as very valuable by the practitioners, management and service users. At the same time, this created some frustration among researchers because it required a lot of time and slowed down the research project.

According to Thompson et al. (2009), this fragile balance between 'giving and taking' may change over time and evolve into less fragile 
social mores that form the basis of social interaction and reciprocal exchange in the collaboration. This is also acknowledged by authors such as Ansell and Gash (2008). In the ACC, we could observe some evolving loop of trusts between the research institutes and the organisation for child and family social work. For example, practitioners learned to trust that their need to improve and learn would be recognised, while researchers learned that the scientific quality of the research project was also acknowledged by the management of the organisation for child and family social work.

Such trust loops are, however, threatened by various elements, such as the power differences between researchers, managers, social workers and service users. At different times during the research project, the management, for instance, gave more power to the researchers than to the other stakeholders, and expected them to make judgements such as: 'this is good practice', 'this is bad practice' or 'this is a good social worker', 'this is a bad social worker'. This threatened the trust between the researchers and the social workers. At the same time, social workers sometimes found it hard to hear the comments of service users, labelling them as resistance or 'just another opinion'. Transparent agreements (e.g. about anonymising the research material, about differences between evaluation and collaborative learning) and frequent formal and informal contacts at different levels of the ACC helped to foster a safe climate and equal dialogue between the stakeholders.

Another aspect that influences these trust loops is the available time and the funding of the project. As stated by various authors about all sorts of collaborative partnerships (e.g. Ansell and Gash, 2008; Imperial, 2005; Warner, 2006), building trust requires time and cannot be rushed. This time is not always available. Funding for partnerships in Flanders is often temporary and, as research material is more complex and messy than traditional positivist research projects, not always easily renewed.

\section{Conclusion and discussion}

Partnership structures between research and practice are broadly acknowledged for their potential value to move beyond the persistent research-practice gap in social work (Young et al., 2002; Nutley et al., 2003; Osterling and Austin, 2008; Mitchell et al., 2009; Wehrens, 2013). A very valuable example is that of the organisational excellence model by Nutley et al. (2003). However, to implement this model in local social work practice requires a lengthy, messy but also very rich process at different levels and over various dimensions. Based on this project, we can add three elements that are important when realising this organisational excellence model in day-to-day social work practice. 
First, as illustrated by this project, it is important but not sufficient to have a formal collaborative governance structure that allows participants to address problems, jointly make decisions and develop a mutual framework (see also Thompson et al., 2009). Although a formal structure facilitates interactions, it does not automatically render them meaningful. Frequent informal contacts between the different stakeholders and knowledge brokering by a science practitioner turn out to be very important to building trust, breaking down stereotypes (see also Ansell and Gash, 2008) and enhancing negotiation processes between the different groups. Second, to move further from governance into action, a research-practice partnership needs concrete research projects. By analysing concrete research material collaboratively and engaging in interactions with other stakeholders (practitioners, researchers, managers, user organisations, policy makers), each partner gradually learns to listen to one another's viewpoints, and to speak up and share their ideas. In our particular project, these interactions triggered different unforeseen initiatives at the organisation for child and family social work (like joint multi-stakeholder brainstorming sessions, creative projects with youngsters), which in turn enhanced interactions at the ACC. Surprisingly, the available literature on research-practice partnerships mainly presents broad theoretical and conceptual frameworks, but does not elaborate on the small, specific research projects that are implemented within such frameworks. Third, to realise the potential of a research-practice partnership, it turned out to be important not to ignore or try to resolve the differences between the different stakeholders, but to build a general framework of agreement and mutuality in which these differences can safely co-exist and negations can take place. It is precisely the tension between each stakeholder's own identity, viewpoints and self-interest that holds within a potential dynamism and enhances creativity among the different stakeholders.

The process of building this collaborative structure, investing in informal contacts with the different stakeholders, knowledge brokering, setting out research projects and building a general framework of agreement and mutuality requires time and cannot be rushed. Such time is often not available, as the funding for collaborative partnerships in Flanders is often project-based and thus temporary. Research into the complex, multilevel and multidimensional nature of research-practice partnerships, in order to identify and understand the necessary conditions (e.g. the role of the knowledge broker, the nature of research projects within this partnerships, the role of organisational culture) and the time it takes to build a sustainable partnership, would help to open up this discussion. 


\section{References}

Ansell, C. and Gash, A. (2008) 'Collaborative governance in theory and practice', Journal of Public Administration Research and Theory, 18(4), pp. 543-71.

Belkhodja, O., Amara, N., Landry, R. and Ouimet, M. (2007) 'The Extent and Organizational Determinants of Research Utilization in Canadian Health Services Organizations', Science Communication, 28(3), pp. 377-417.

Best, A. and Holmes, B. (2010) 'Systems thinking, knowledge and action: Towards better models and methods', Evidence \& Policy: A Journal of Research, Debate and Practice, 6(2), pp. 145-59.

Biesta, G. (2007) 'Why "what works" won't work: Evidence-based practice and the democratic deficit in educational research', Educational Theory, 57(1), pp. 1-22.

Blom, B. and Morén, S. (2010) 'Explaining social work practice: The CAIMER Theory', Journal of Social Work, 10(1), pp. 98-111.

De Goede, J. (2011) 'Knowledge in process', Ph.D. thesis, Tilburg University.

Edelenbos, J. and Klijn, E. H. (2005) 'Managing Stakeholder Involvement in Decision Making: A Comparative Analysis of Six Interactive Processes in the Netherlands', Journal of Public Administration Research and Theory, 19(3), pp. $417-46$.

Garretsen, H., Bongers, I., de Roo, A. and van de Goor, I. (2007) 'Bridging the gap between science and practice: Do applied academic centres contribute to a solution? A plea for international comparative research', Journal of Comparative Social Welfare, 23(1), pp. 49-59.

Gerschick, T. J., Isreal, B. A. and Checkoway, B. N. (1990) Means of Empowerment in Individuals, Organizations and Communities: Report from a Retrieval Conference, Ann Arbor, MI, University of Michigan, Centre for Research on Social Organizations.

Gray, B. (1989) Collaborating: Finding Common Ground for Multiparty Problems, San Francisco, CA, Jossey-Bass.

Gray, M., Sharland, E., Heinsch, M. and Schubert, L. (2015) 'Connecting research to action: Perspectives on research utilisation', British Journal of Social Work, 45(7), pp. 1952-67.

Greenhalgh, T., Robert, G., Macfarlane, F., Bate, P. and Kyriakidou, O. (2004) 'Diffusion of Innocations in Service Organizations: Systematic Review and Recommendations', Milbank Q., 82(4), pp. 581-629.

Gredig, D. and Sommerfeld, P. (2008) 'New proposals or generating and exploiting solution-focussed knowledge', Research on Social Work Practice, 18(4), pp. 292-300.

Guston, D. (1999) 'Stabilizing the boundary between US politics and science: The role of the office of technology transfer as a boundary organization', Social Studies of Science, 29(1), pp. 87-111.

Guston, D. (2001) 'Boundary organizations in environmental policy and science: An introduction', Science, Technology \& Human Values, 26(4), pp. 399-408.

Hoeijmakers, M., Harting, J. and Jansen, M. (2013) 'Academic Collaborative Centre Limburg: A platform for knowledge transfer and exchange in public health policy, research and practice?', Health Policy, 111(2), pp. 175-83.

Huxham, C. and Vangen, S. (2000) 'Ambiguity, complexity, and dynamics in the membership of collaboration', Human Relations, 53, pp. 771-801. 
Imperial, M. (2005) 'Using collaboration as a governance strategy: Lessons from six watershed management programs', Administration \& Society, 37(1), pp. 281-320.

Innes, J. E. (1999) 'Evaluating consensus building', in Suskind, L., McKearnan, S. and Thomas-Larmer, J. (eds), The Consensus Building Handbook: A Comprehensive Guide to Reaching Agreement, Thousand Oaks, CA, Sage.

Jansen, M. W. J., van Oers, H., Middelweerd, M. D. R., van de Goor, I. and Ruwaard, D. (2015) 'Conditions for sustainability of academic collaborative centres for public health in the Netherlands: A mixed methods design', Health Research Policy and Systems, 13(1), p. 36.

Kazi, M. (2000) 'Contemporary perspectives in the evaluation of practice', British Journal of Social Work, 30(6), pp. 755-76.

Kazi, M. (2003) 'Realist evaluation for practice', British Journal of Social Work, 33(6), pp. 803-18.

Kitson, A. (2009) 'Knowledge translation and guidelines: A transfer, translation or transformation process?', International Journal of Evidence-Based Healthcare, 7(2), pp. 124-39.

Lomas, J. (2007) 'The in-between world of knowledge brokering', British Medical Journal, 334(7585), pp. 129-34.

Longhofer, J., Floersch, J. and Hoy, J. (2013) Qualitative Methods for Practice Research, Oxford, Oxford University Press.

Mitchell, P., Pirkis, J., Hall, J. and Haas, M. (2009) 'Partnerships for knowledge exchange in health services research, policy and practice', Journal of Health Services Research Policy, 14(2), pp. 104-11.

Molleman, G. and Fransen, G. (2012) 'Academic collaborative centres for health promotion in the Netherlands: Building bridges between research, policy and practice', Family Practice, 29(Suppl 1), pp. i157-62.

Nutley, S., Walter, I. and Davies, H. (2003) 'From knowing to doing', Evaluation, 9(2), pp. 125-48.

Nutley, S., Walter, I. and Davies, H. (2009) 'Promoting evidence based practice: Models and mechanisms from cross-sector review', Research on Social Work Practice, 19(5), pp. 552-9.

Osterling, K. L. and Austin, M. J. (2008) 'Substance abuse interventions for parents involved in the child welfare system: Evidence and implications', Journal of Evidence Based Social Work, 5(1-2), pp. 157-89.

Parker, J. and Crona, B. (2012) 'On being all things to all people: Boundary organizations and the contemporary research university', Social Studies of Science, 42(2), pp. 262-89.

Pawson, R. (2006) Evidence Based Policy: A Realist Perspective, London, Sage.

Pawson, R. (2014) The Science of Evaluation: A Realist Manifesto, London, Sage.

Richmond, M. E. (1917) Social Diagnosis, New York, Russell Sage Foundation.

Rubin, A. (2014) 'Efforts to bridge the gap between research and practice in social work: Precedents and prospects: Keynote address at the Bridging the Gap Symposium', Research on Social Work Practice, 25(4), pp. 408-14.

Senge, P. (1990) The Fifth Discipline: The Art and Practice of the Learning Organization, New York, Doubleday.

Thompson, C., McCaughan, D., Cullum, N., Sheldon, T. A., Mulhall, A. and Thompson, D. R. (2001) 'Research information in nurses' clinical decision-making: What is useful?', Journal of Advanced Nursing, 36(3), pp. 376-88. 
Thompson, C., Perry, J. L. and Miller, T. K. (2009) 'Conceptualizing and measuring collaboration', Journal of Public Administration Research and Theory, 19(1), pp. $23-56$.

Van Egmond, S. (2010) 'Science and policy in interaction: On practices of science policy interactions for policy-making in health care', Ph.D. thesis, Rotterdam, Erasmus University.

Van Regenmortel, T., Steenssens K. and Steens, R. (2016) 'Empowerment onderzoek: een kritische vriend voor sociaal werkers' [Empowerment research. A critical friend for social workers], Journal of Social Intervention, 25(3), pp. 4-23.

Warner, J. F. (2006) 'More sustainable participation? Multi-stakeholder platforms for integrated catchment management', Water Resources Development, 22(1), pp. $15-35$.

Wehrens, R. (2013) 'Beyond two communities. The co-production of research, policy and practice in collaborative public health settings', Ph.D. thesis, Rotterdam, Erasmus University.

Young, K. D., Ashby, D., Boaz, A. and Grayson, L. (2002) 'Social science and the evidence based policy movement', Social Policy and Society, 1(03), pp. 215-24.

Zimmerman, M. A. (1990a) 'Taking aim on empowerment research: On the distinction between psychological and individual conceptions', American Journal of Community Psychology, 18(1), pp. 169-77.

Zimmerman, M. A. (1990b) 'Toward a theory of learned hopefulness: A structural model analysis of participation and empowerment', Journal of Research in Personality, 24(1), pp. 71-86.

Zimmerman, M. A. (1995) 'Psychological empowerment: Issues and illustrations', American Journal of Community Psychology, 23(5), pp. 581-99.

Zimmerman, M. A. (2000) 'Empowerment theory: Psychological, organizational and community levels of analysis', in Rappaport, J. and Seidman, E. (eds), Handbook of Community Psychology, New York, Plenum. 